\title{
Polar and Equatorial Aspects of Map Projections?
}

\author{
Miljenko Lapaine $^{\mathrm{a},}{ }^{*}$, Nedjeljko Frančula ${ }^{\mathrm{b}}$ \\ ${ }^{a}$ University of Zagreb, Faculty of Geodesy, mlapaine@geof.hr \\ ${ }^{b}$ University of Zagreb, Faculty of Geodesy, nfrancul@geof.hr \\ * Corresponding author
}

\begin{abstract}
There is no standard or generally accepted terminology of aspect in the theory of map projections. The term is probably derived from the concept that a graticule is produced by perspective projection of the meridians and parallels on a sphere onto a developable surface. Developable surfaces are widely accepted, and it is almost impossible to find a publication that deals with map projections in general and without developable surfaces story. If found, it usually classifies projections as cylindrical, conical and azimuthal, and applies developable surfaces to define the projection aspect. This paper explains why applying developable surfaces in the interpretation of map projections is not recommended, nor defining the aspect of all projections by the position of a midpoint as polar, equatorial, or oblique. In fact, defining a projection aspect this way is invalid in general, and obscures the fact that the aspect depends on the class to which a particular map projection belongs.
\end{abstract}

Keywords: map projection, equatorial aspect, polar aspect

\section{Introduction}

A detailed overview of the literature on aspects of map projections, definition and divisions into normal, transverse and oblique using the pseudomeridians, pseudoparallels and axis of each projection, with all the necessary formulas, has been given in a paper by Lapaine and Frančula (2016). It says that the terms 'polar and equatorial aspects' of map projections are not recommended. In another short paper without a formula, all the necessary definitions are given (Frančula, Lapaine 2018). This article again urges caution regarding problems with the terms 'polar and equatorial aspects'. Although it was observed many years ago that the terms are illogical (FIG 1963, FIG 1971), they are still used (Clarke 2015) and even recommended (Kessler 2018) in the literature on map projections.

The following definition appears in the Glossary of the Mapping Sciences (ASCE, ACSM, ASPRS 1994): "aspect - (1) The apparent position of a (cartographic) graticule in relation to the longitudes and parallels of latitude that they represent. Also called a case of a map projection. The term is derived from, and relates to, the concept that a graticule is produced by actually projecting the meridians and parallels on an ellipsoid onto a developable surface. The appearance of the graticule then depends on how the pattern of meridians and parallel is positioned with respect to the developable surface. Terminology is not uniform. However, that aspect which produces the simplest graticule (e.g., meridians and parallels are represented as straight lines) is commonly termed the normal aspect of the map projection and of the graticule. The aspect produced by rotating the ellipsoid through $90^{\circ}$ from its position in normal aspect is then the transverse aspect, and any rotation between $0^{\circ}$ and $90^{\circ}$ produces an oblique aspect. (2) The appearance of a graticule according as certain meridians or parallels of latitude are represented as lines of zero distortion (this appearance is then called the normal aspect), the line of zero distortion is perpendicular to the line which would be the line of zero distortion in the normal aspect (this appearance is called the transverse aspect), or neither relation holds (this appearance is then called an oblique aspect.) This set of rules for naming aspects is often applied to graticules not produced by true projection. (3) The appearance of a graticule according as the center of the graticule represents a pole of the rotational ellipsoid (polar aspect), a point on the equator (meridional aspect or equatorial aspect) or neither (oblique aspect). If the oblique aspect of a map projection is not symmetric about the central meridian, the aspect is called a skew oblique aspect. There is, however, no standard or generally accepted terminology for the concept of aspect. (4) The orientation of a set of directed axes associated with a scene, with respect to the image of that set of axes. For example, an image is said to be in an inverted aspect if the imaged set of axes is inverted with respect to the set of axes associated with the scene."

We see that there is no standard or generally accepted terminology for the concept of aspect. Furthermore, different definitions of aspects can lead to confusion.

Wray (1974) published a paper in which he explains the seven aspects of a general map projection. Although the paper is mathematically correct, its approach is relatively complex and has not been widely used.

In Russian literature (Vakhrameeva et al. 1986, Bugayevsky 1998, Serapinas 2005) we meet the concepts of normal, transverse and oblique cartographic network, as well as normal, transverse and oblique map projections. 
According to Lapaine and Frančula (2016), to define azimuthal, conic, cylindrical and other groups of projections, and then the aspect of these projections, a network of pseudomeridians and pseudoparallels must be used. The network can be created through an imaginary rotation of the network of meridians and parallels in any other position (Fig. 1). We have called the straight line which passes through the poles of the network of pseudomeridians and pseudoparallels the axis of the projection.

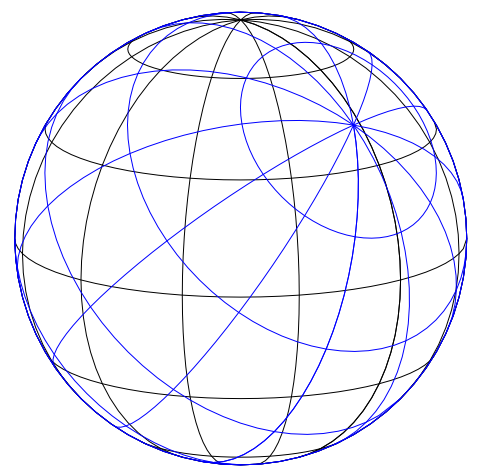

Figure 1. Network of meridians and parallels (black) and network of pseudomeridians and pseudoparallels (blue) (Lapaine, Frančula 2016).

The aspect of a projection is the position of the axis of the projection in relation to the axis of rotation of the Earth's sphere. The aspect may be normal, transverse, or oblique.

In the normal aspect, the axis of the projection corresponds to the axis of the Earth's sphere, and the graticule of pseudomeridians and pseudoparallels corresponds to the graticule of meridians and parallels.

In the transverse aspect, the axis of the projection is perpendicular to the axis of the Earth's sphere.

The oblique aspect is neither normal nor transverse.

Instead of normal, transverse or oblique aspect of a projection, we can say shorter: normal, transverse or oblique map projection.

\section{Discussion}

In the FIG three-language dictionary (French, German, English), we find this (FIG 1963):

\section{aspect direct, aspect normal}

Definition: C'est la projection initiale. On complète parfois ces projections par l'épithète polaire (symétrie par rapport à un pôle) ou par celle d'équatoriale (symétrie par rapport a l'equateur)

French: aspect direct ou normal

German: normalachsig; polständig

English: normal case

French: aspect polaire

German: polachsig; polar

English: polar case

From this entry, it is clear that there is some irregularity regarding names. The same aspect of a projection can be normal, polar and equatorial. Three different names for the same term are certainly unnecessary and may lead to confusion.

In the FIG professional dictionary (Fachwörterbuch, Heft 8 - Kartographie, Kartenvervielfältigung) (FIG 1971) we find this entry:

German: normale Abbildung; auch normalachsige Abbildung; polachsige Abbildung; polare Abbildung; polständige Abbildung

Definition: Eine kartographische Abbildung mit normaler Lage der Abbildungsfläche.

English: normal projection; polar projection

French: projection normale; projection polaire

German: transversale Abbildung; äquatorachsige Abbildung; äquatorständige Abbildung; querachsige Abbildung

Definition: Eine kartographische Abbildung mit transversaler Lage der Abbildungsfläche.

English: transverse projection; equatorial projection

French: projection transverse; projection équatoriale

The first thing to note here is that the definitions of normal and transverse projections are based on the notion of position of the mapping surface (Lage der Abbildungsfläche). There are a number of other reasons why we argue in favour of excluding the interpretation of map projections using auxiliary, intermediate or developable surfaces in general. Here are some of them (Frančula, Lapaine 2018):

- The authors of the oldest cylindrical and conic projections did not define their projections using auxiliary or developable surfaces. In the 16th century, Mercator did not use a cylindrical surface to define the cylindrical projection which bears his name today, and in the 18th century, Lambert did not use a conic surface to define the projection today known as Lambert's conformal conic projection. On the contrary, having performed the equations for the projection, he said that a map produced in it could be rolled up into a cone.

- According to Snyder (1993), developable surfaces are mentioned for the first time in the cartographic literature in 1863 by D'Avezac in Coup d'oeil historique sur la projection des cartes de géographie. D'Avezac deals with the classifications of map projections and proposes the general term constructions for all map projections, dividing them into projections which follow the perspective law, developments under the condition of correlation between the sphere and the developable surface and representation systems based on purely conventional combinations. He writes, "Cependant, si l'on voulait tenter de rétablir quelque exactitude dans la nomenclature relative à cet objet, c'est le mot de construction qu'il faudrait adopter comme appellation générale, comprenant, en trois catégories distinctes, les projections assujetties aux lois de la perspective, les développements subordonnés aux conditions de correlation de la sphère avec les surfaces développables, et les systèmes de représentation fondés sur des combinaisons purement conventionnelle." 
- Authors today who go into detail about map projections using intermediate surfaces are perhaps not aware that they are introducing double mapping into the theory of map projections. First, the Earth's sphere is mapped onto an auxiliary surface, then transformed into a map in the plane using another method, for example, development. Double mapping has a role in the theory of map projections, but only in certain special cases.

- In the context of classifying projections as conic, cylindrical and azimuthal/planar, it is not natural to use a plane as a developable surface if the developable surface can be developed in the plane. What does developing a plane in the plane mean? Development is isometry, so from the cartographic point of view, nothing would change.

- The use of developable surfaces leads to secant projections, that is, projections onto an auxiliary developable surface which intersects the sphere, with the conclusion that azimuthal projections can have a maximum of one standard parallel, and conic projections a maximum of two. This is erroneous, as there are azimuthal and conic projections with more standard parallels (Lapaine 2015).

- Authors who understand map projections as mappings using intermediate surfaces often distinguish between contact and intersection. So, as a rule, the curve of intersection is also a curve with no distortion. They take this for granted, with no proof. However, it has been shown not to be the case at all (Lapaine 2017a, b).

- Developing an auxiliary surface in the plane preserves distance (isometry). This means that two parallels selected as standard parallels in all normal aspect projections of the Earth's sphere of a given radius would be mapped to parallels at the same distance from each other. Of course, this is not true, as can be easily tested.

- It is possible to understand each other perfectly without introducing auxiliary surfaces and their contact or intersection with the sphere, and to speak of projections without distortion, or with zero-distortion at one point, or along one curve (e.g. a parallel), or along several curves (e.g. parallels).

- Though it is a nice idea to explain mapping a sphere onto the surface of a cylinder or cone, if the mathematical basis of the process is overlooked, it leads to erroneous claims, of which the authors are probably unaware. Instead of a conceptual approach which is partially mistaken, we need to return to reality and not shun mathematics. We should remember that in the not-too-distant past, the study of map projections was called mathematical cartography.

The second thing to note, as seen from the definition in the FIG professional dictionary (FIG 1971), is that the normal projection is the same as the polar projection, and the transverse projections coincide with the equatorial. So, we have two different names for the same terms, which can create confusion.
Snyder (1987, p. 29) uses the terms polar and equatorial aspects exclusively for azimuthal projections. For cylindrical and most other projections, he uses the terms normal (regular), transverse, and oblique aspects. In his book on the history of map projections (Snyder 1993) he rarely uses the term aspect. Instead, he prefers the terms transverse and oblique projections. The terms polar and equatorial projections are used only for azimuthal projections. The term transverse projection is used for cylindrical, pseudo-cylindrical and polyconic projections, and the term oblique projection for azimuthal, conic, cylindrical, pseudoazimuthal, and some others.

The definition of polar and equatorial aspects of map projection is well defined in ESRI's GIS Dictionary because it applies only to azimuthal projections. For the equatorial aspect, it says this is an azimuthal projection in which the centre point of the mapping area is on the equator, while for the polar aspect, the central point is the north or south pole. There is no definition of an oblique aspect where the centre point is at any point between the pole and the equator but is in the form of an oblique projection associated with cylindrical projections. " $A$ planar or cylindrical projection whose point of tangency is neither on the equator nor at a pole." A picture of a cylinder that touches the Earth's sphere along an arbitrary large circle is attached (Esri 2018). This definition applies only to azimuthal and cylindrical projections and has several shortcomings. First, it contains the term point of tangency, which includes some azimuthal and cylindrical projections only because it obviously does not include azimuthal and cylindrical projections for which there is no point of tangency, such as secant projections. In addition, how are we to define the oblique aspect or oblique projection (and transverse) for projections that are not defined by auxiliary surfaces, e.g. pseudocylindrical, pseudoconic, or Winkel's triple projection? In any event, we can conclude that this is an incomplete and useless definition.

Clarke (2015) defines an aspect as "the angle between a projection's central directional line and the equator".

The first problem lies in the fact that we do not know what the projection's central directional line is; there is no definition of this, nor is the term generally known. Therefore, nobody knowns what an aspect is. Clarke then defines the equatorial aspect as, "an aspect or orientation of a world map so that the equator as shown on the map runs from left to right, and the poles are at the top and bottom". Therefore, for Clarke, the aspect exists only for world maps. Further, according to his definition, both maps shown in Figures 2 and 3 have the same equatorial aspect. That was certainly not his intention.

That the equatorial aspect cannot be uniquely defined for cylindrical projections is illustrated in Figures 2 and 3. Figure 2 is a world map in a normal equidistant cylindrical projection. Since the equator is at the map centre, it should be an equatorial aspect. Figure 3 is a world map in transversal equidistant cylindrical projection. On this map, the equator is also at the centre of the map, so it should be the equatorial aspect. A similar illustration for the Mercator projection can be 
found on Wikipedia (2018). Of course, somebody could argue that the poles are not at the top and bottom on Fig. 3 , but they are located up and down for sure.

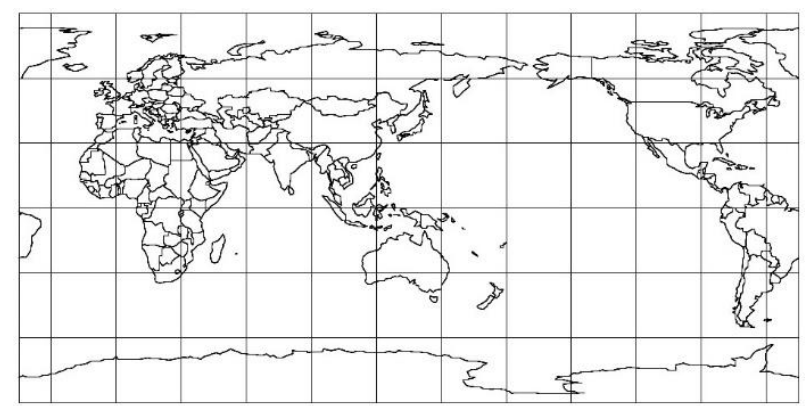

Figure 2. World map in normal aspect of equidistant cylindrical projection.

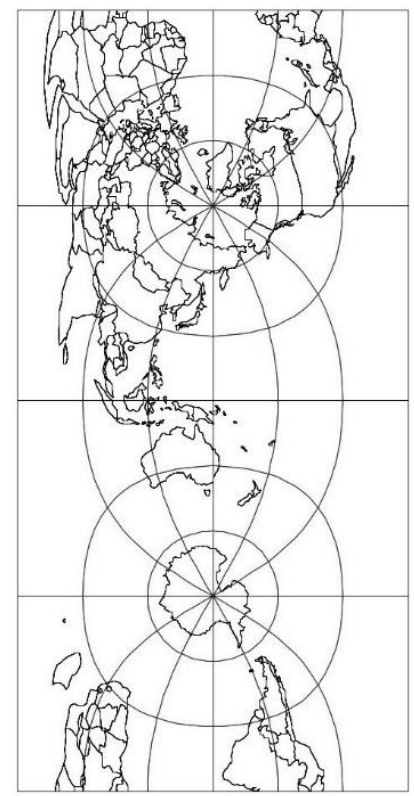

Figure 3. World map in transverse aspect of equidistant cylindrical projection.

However, all the projections in the same projection group, e.g. cylindrical, have the same form of graticule in one aspect, so there are obviously two different aspects in Figures 2 and 3. Similarly, it can be shown that the equatorial aspect cannot be uniquely defined for other projections (see, for example, Figures 4 and 5), with the exception of azimuthals.

Kessler (2018) defines the aspect of the projection according to the position of the geographic centre of the map and distinguishes the equatorial, oblique and polar aspects. He says, "Words relating to a projection's aspect, such as "normal," "polar," and "equatorial," also appeared in almost every textbook across the different eras. Interestingly, the specific words associated with "normal aspect" saw considerable variation across the eras. For example, normal aspect was often defined according to the typical aspect in which a projection was shown (e.g., an azimuthal projection was typically shown as cantered on a pole whereas a cylindric projection was typically shown as aligned along the equator). Thus, "normal aspect" was not consistently applied to one particular aspect but was dependent upon the projection class and could be easily misunderstood unless the reader knew the particular projection class being referenced".

At first glance, Kessler's explanation seems correct. However, there is still a problem, because he does not define the aspect. On the other hand, he is right when he says that the aspect depends on the class to which the observed projection belongs.

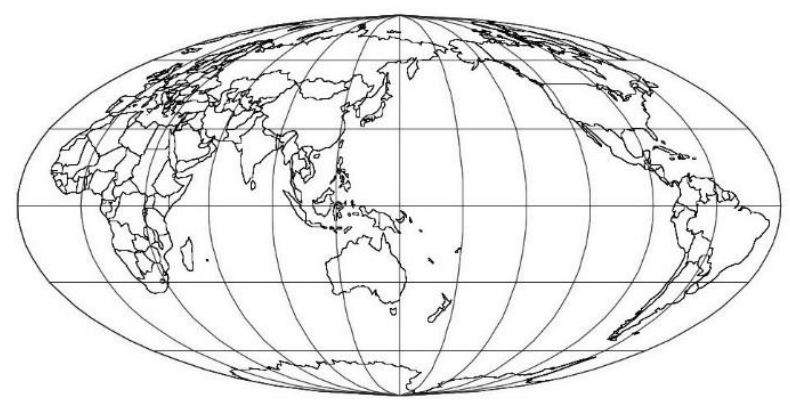

Figure 4. World map in normal aspect Mollweide projection.

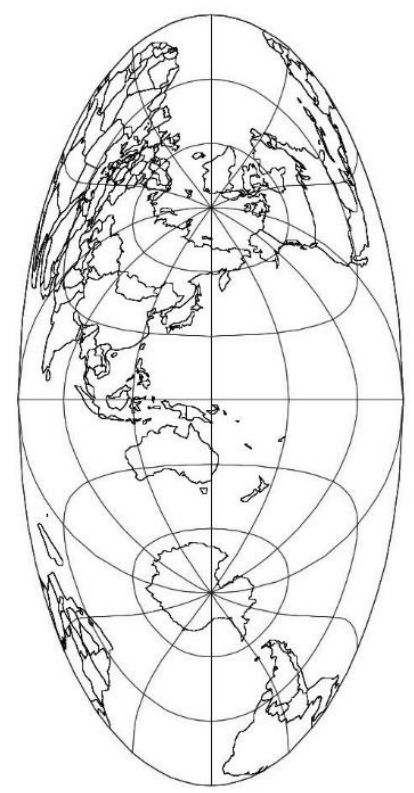

Figure 5. World map in transverse Mollweide projection.

In references on map projections, the aspect is sometimes defined according to the area represented in the central part of a map (Snyder 1987, Grafarend and Krumm 2006, Fenna 2007, Kessler 2018). According to this definition, the aspect can be polar, equatorial or oblique. Adopting familiar terms such as "equatorial," "oblique," and "polar" to define a projection's aspect would make it clear to the student where the geographic centre of the map is located (Kessler 2018). On the other hand, it is instructive to quote Lee (1944): "According to whether the origin of the projection is a pole, a point on the equator or some other point, they have been called polar, equatorial, and oblique; while according to whether the plane of projection is (or is parallel to) the equator, a 
meridian or the horizon of some point, they have been called equatorial, meridian, and horizon. Thus equatorial is used in two conflicting senses. Since the terms direct, transverse and oblique can be applied to these projections as to all others, it would seem advisable to abandon the use of terms about which there is no general agreement." If we mean by polar aspect the representation of a pole in the map centre, then the polar aspect is not defined by the position of the projection axis in relation to the geographic sphere parameterization axis. So normal azimuthal and transverse cylindrical projections can be in the polar aspect. Likewise, if we mean by the equatorial aspect the representation of the equator in the map centre, then the equatorial aspect is not defined by the position of the projection axis in relation to the geographic sphere parameterization axis. For example, transverse azimuthal and normal cylindrical projections can be in the equatorial aspect. The projections in Figures $6 \mathrm{a}$ and $6 \mathrm{~b}$ might be considered polar projections by one person, but equatorial projections by another. This example shows that the definitions of the polar and equatorial aspects are imprecise and ambiguous, and should be avoided.

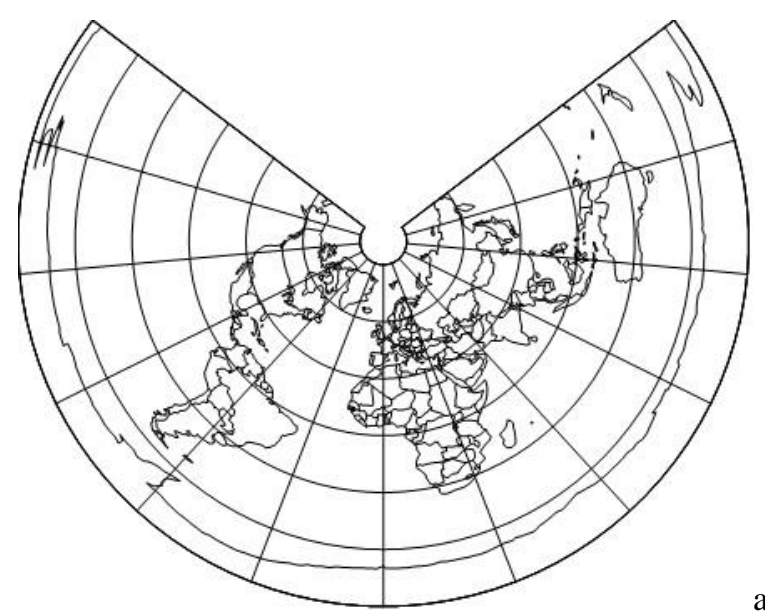

a)

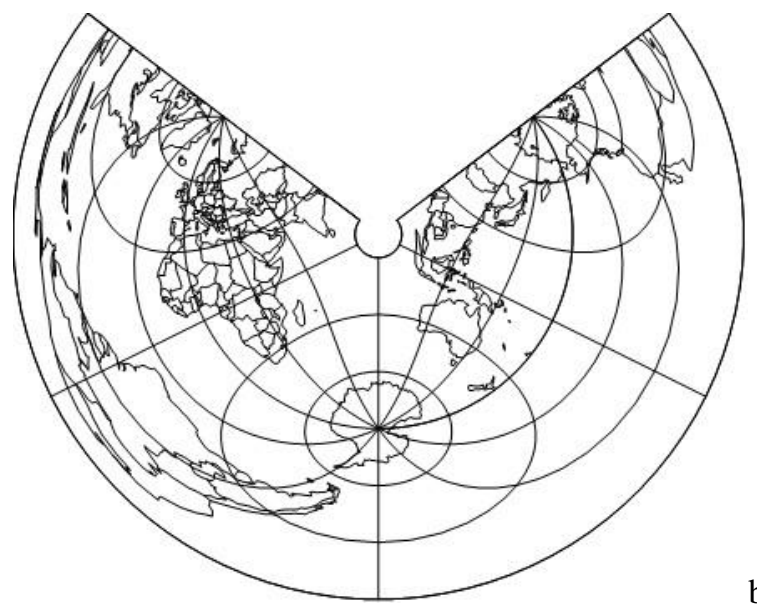

b)

Figure 6. Normal (a) and transverse (b) conic projection (equidistant along meridians). Illustration of problematic choices of polar or equatorial aspects.

\section{Conclusion}

The application of developable surfaces was mentioned in the literature on map projections for the first time in the late 19th century (D'Avezac 1863). Developable surfaces are widely accepted and today it is difficult to find a publication that deals with map projections in general, where the author does not resist temptation and begin to consider using developable surfaces. The classification of projections into cylindrical, conical and azimuthal usually follows, with the application of developable surfaces to the definition of the projection aspect. In this paper we have given nine reasons why we do not recommend applying developable surfaces in the interpretation of map projections.

Terms such as normal, transverse, oblique aspect, or normal, transverse and oblique projection can be applied without any restrictions to all kinds of map projections if we accept and apply our approach (Lapaine and Frančula 2016). We do not recommend the aspects of all projections to be defined by the position of a midpoint as polar, equatorial, and oblique aspect, because this way of defining the projection aspect is not valid for all projections. In addition, such a classification does not make much sense, because everyone can see what is in the centre of the map, and this obscures the fact that the aspect depends on the class to which a particular map projection belongs.

\section{Acknowledgements}

The authors wish to thank the anonymous reviewers for their valuable comments.

\section{References}

ASCE, ACSM, ASPRS (1994). Glossary of the Mapping Sciences, American Society of Civil Engineers, American Congress on Surveying and Mapping, American Society for Photogrammetry and Remote Sensing, Maryland, New York.

Bugayevskiy L. M. (1998). Matematicheskaya kartografiya, Moscow, Zlatoust, p. 400 (In Russian)

Clarke, K. C. (2015). Maps \& Web Mapping. Kindle Edition.

D'Avezac M-AP de Castera-Macaya (1863). Coup d'oeil historique sur la projection des cartes de géographie. Imprimerie de E. Martinet, Paris.

Esri (2018). Technical Suport - GIS Dictionary. https://support.esri.com/en/other-resources/gisdictionary (accessed 10 Nov 2018)

Fenna, D. (2007). Cartographic Science, CRC Press, Taylor \& Francis Group, Boca Raton.

FIG (1963). Dictionaire multilingue de la F. I. G., N. V. Uitgeverij, Argus, Asterdam.

FIG (1971). Fachwörterbuch, Heft 8 - Kartographie, Kartenvervielfältigung, Verlag des Instituts für Angewandte Geodäsie, Frankfurt a. M.

Frančula, N., Lapaine, M. (2018). Auxiliary Surfaces and Aspect of Projection / O pomoćnim plohama i aspektu projekcije. Kartografija i geoinformacije 17, 29, 84-89. 
http://kig.kartografija.hr/index.php/kig/article/view/820 (accessed 12 Nov 2018).

Grafarend, E. W., Krumm, F. W. (2006). Map Projections, Springer, Berlin.

Kessler, F. (2018). Map Projection Education in Cartography Textbooks: A Content Analysis. Cartographic Perspectives Number 90, 6-30. http://dx.doi.org/10.14714/CP90.1449 (accessed 14 Nov 2018).

Lapaine, M. (2015). Multi Standard-Parallels Azimuthal Projections, in: Cartography - Maps Connecting the World, C. Robbi Sluter, C. B. Madureira Cruz, P. M. Leal de Menezes (Eds.), Springer International Publishing, Series: Publications of the International Cartographic Association (ICA), doi 10.1007/978-3319-17738-0_3

Lapaine, M. (2017a). Standard Parallel and Secant Parallel in Azimuthal Projections, Kartografija i geoinformacije, Vol. 16, No. 28, 73-88.

Lapaine, M. (2017b). Standard Parallels and Secant Parallels in Conic Projections, SJCE, Scientific Journal of Civil Engineering, vol. 6, No. 2, 127-134.

Lapaine, M., Frančula, N. (2016). Map projections aspects. International Journal of Cartography 2, 1, 3858, doi 10.1080/23729333.2016.1184554 (accessed 12 Nov 2018).

Lee, L. P. (1944). The nomenclature and classification of map projections. Empire Survey Review. VII (51): 190200. doi:10.1179/sre.1944.7.51.190

Serapinas B. B. (2005). Matematicheskaya kartografiya: Uchebnik dlya vuzov. Moscow, izd. Akademiya, 336 p. (In Russian)

Snyder, J. P. (1987). Map Projections - A Working Manual. U.S. Geological Survey, Professional Paper 1395 https://pubs.usgs.gov/pp/1395/report.pdf (accessed 10 Nov 2018).

Snyder, J. P. (1993). Flattening the Earth - Two Thousand Years of Map Projections. The University of Chicago Press.

Vakhrameeva L. A., Bugayevskiy L. M., Kazakova Z. L. (1986). Matematicheskaya kartografiya. Moscow, izd. Nedra, 289 p. (In Russian).

Wikipedia (2018). Map Projection (accessed 25 Nov 2018).

Wray, Th. (1974). The seven aspects of a general map projection. Cartographica, Vol. 11, No. 2, 1-72. 